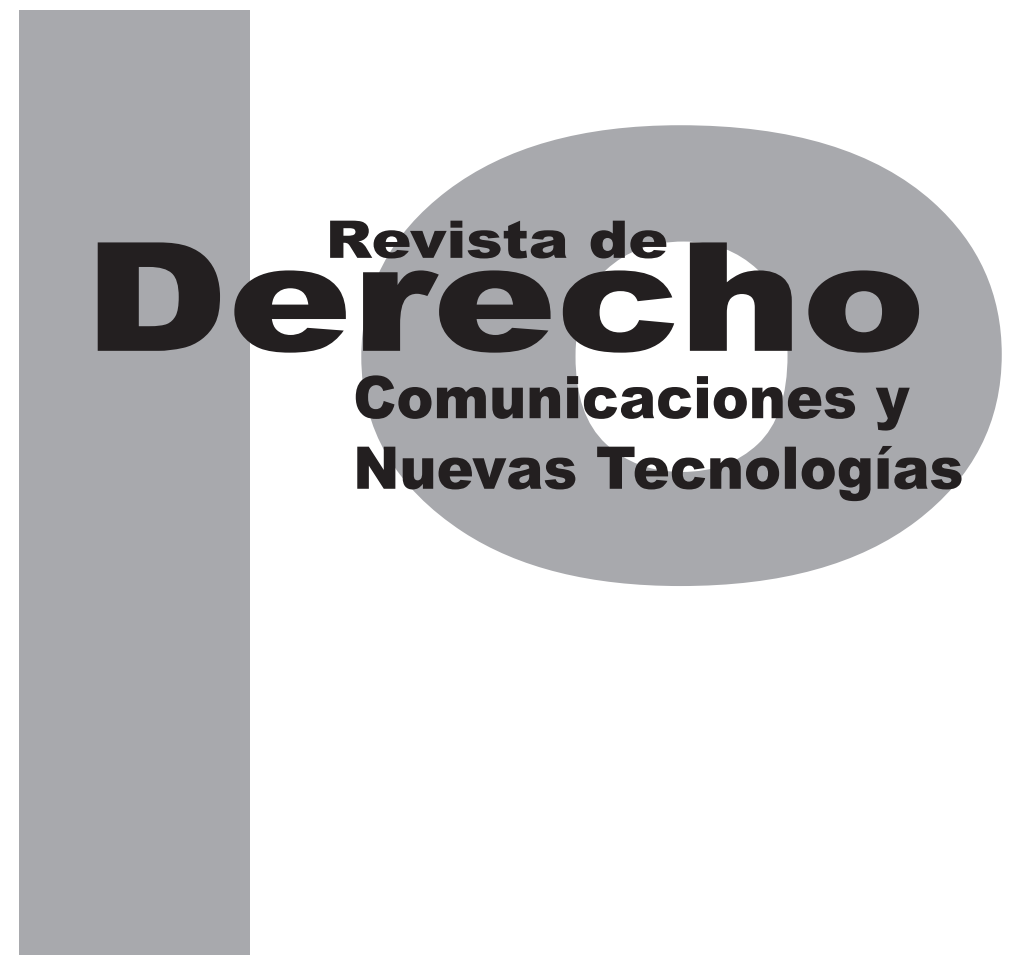

LOS DERECHOS DE AUTOR EN EL ENTORNO DIGITAL Y EL INTERNET EN COLOMBIA: UNA MIRADA AL ESTADO DEL ARTE ACTUAL Y SUS PRINCIPALES PROBLEMAS

\author{
LILIANA GALINDO DÍAZ \\ ANDREa MARTínez DEVIa \\ RODOLFO YÁÑEZ OTÁLORA
}

Universidad de los Andes

Facultad de Derecho

Revista de Derecho, Comunicaciones y Nuevas Tecnologías

No.10, Julio - Diciembre de 2013. ISSN 1909-7786 


\title{
Los derechos de autor en el entorno digital y el Internet en Colombia: una mirada al estado del arte actual y sus principales problemas ${ }^{*}$
}

\author{
Liliana Galindo Díaz** \\ Andrea Martínez Devia*** \\ Rodolfo Yáñez Otálora ${ }^{* * *}$
}

\section{RESUMEN}

En Colombia existe un gran vacío respecto de la protección del derecho de autor en medios digitales, dado que se cuenta con una legislación débil sobre el tema, y los actores relacionados con este campo de la propiedad intelectual no implementan de forma adecuada las herramientas vigentes. Este trabajo estudia esta problemática y presenta unas consideraciones finales sobre algunos cambios que deben implementarse para promover el derecho de autor en el país.
Colombia does not count with a proper copyright protection related to the digital media, due to the fact that there is a weak legislation on the subject, and the actors involved in the field do not properly implement the tools that we have today. This paper studies this problem and establishes some final considerations about the changes that should be implemented in order to improve the copyright protection in Colombia.

Cómo citar este artículo: Galindo Díaz, L., Martínez Devia, A. y Yáñez Otálora, R. (Diciembre, 2013). Los derechos de autor en el entorno digital y el internet en Colombia: una mirada al estado del arte actual y sus principales problemas. Revista GECTI, 10. ${ }^{* *}$ Abogada egresada de la Universidad de Los Andes. Correo: julianavp25@gmail.com

** Abogada de la Universidad de los Andes (2011), con especialización en Derecho Comercial de la misma Universidad (2013). Dos años de experiencia trabajando en temas de propiedad intelectual en la firma OlarteMoure.

*** Abogada de la Universidad de los Andes (2012). Dos años de experiencia trabajando en temas de propiedad intelectual en la firma Clarke \& Modet y en Sullivan Hill Lewin Rez \& Engel, San Diego, California.

***** Abogado de la Universidad de los Andes (2011). Dos años de experiencia trabajando en temas de propiedad intelectual y derecho corporativo en la firma 4Solutions. 
PALABRAS ClAVE: derecho de autor, derechos Keywords: copyright, Related Rights, Internet, conexos, Internet, entorno digital, infracción, Digital Environment, infringement, Internet proproveedores de Internet, usuario, derechos pa- viders, user rights, moral rights, digital business. trimoniales, derechos morales, negocio digital. 


\section{SUMARIO}

Introducción - I. DEFINICIONES - A. Visión general del derecho de autor y derechos conexos - $B$. Ámbito digital - II. SITUACIÓN ACTUAL DEL DERECHO DE AUTOR EN COLOMBIA - A. Ámbito internacional - 1. Convenio de Berna para la Protección de las Obras Literarias y Artísticas - 2. Convención de Roma - 3. Convenio para la Protección de los Productores de Fonogramas - 4. Acuerdo sobre los Aspectos de los Derechos de la Propiedad Intelectual relacionados con el Comercio - 5. Tratados de la oMPI sobre Derecho de Autor (TODA) y sobre Interpretación o Ejecución y Fonogramas (TOIEF) - B. Norma comunitaria - C. Ámbito nacional - 1. Constitución de 1991 - 2. Código Civil colombiano 3. Ley 23 de 1982 - 4. Ley 44 de 1993 - 5. Ley 599 de 2000 y Ley 906 de 2004 - 6. TLC ColombiaEstados Unidos - III. FORMAS DEL NEGOCIO DIGITAL - A. Medios en los que se explota el negocio digital - B. Explotación en línea de industrias protegidas por el derecho de autor - C. Nuevas creaciones en el entorno digital - D. Cómo se licencian los derechos patrimoniales y conexos - E. El Copyleft como alternativa frente a los derechos de autor: (licencias libres, el retorno del control a los creadores) - F. Gestión colectiva - IV. DERECHO COMPARADO - A. Estados Unidos - B. España - V. CONSIDERACIONES FINALES: PAUTAS PARA UNA MEJOR PROTECCIÓN DE LOS DERECHOS DE AUTOR EN EL ENTORNO DIGITAL EN COLOMBIA - Bibliografía. 
Introducción

El derecho de autor debe adaptarse a las nuevas tecnologías, ${ }^{1}$ pues de lo contrario perderá su razón de ser y dejará de perseguir su fin último: el incentivo a los autores para la realización de obras que fomenten la cultura. El director general de la Organización Mundial de la Propiedad Intelectual (oMPI), Sr. Francis Gurry, ha planteado de forma muy clara el problema que se está viviendo con el derecho de autor: "hoy el derecho de autor debe evolucionar para adecuarse a la realidad tecnológica actual, o de lo contrario perderá relevancia". ${ }^{2}$

Esta problemática ha cobrado fuerza en el ámbito internacional y los países, cada vez más, se interesan por hallar la forma de asegurar una protección efectiva a los retos que la incursión de las nuevas tecnologías y las nuevas formas de negocio plantean en lo relativo a los derechos de autor.

Puntualmente, en Colombia existe una gran incertidumbre jurídica respecto de la protección de los derechos de autor de las obras que se encuentran en soportes digitales y se comercializan en Internet, lo cual está afectando a las industrias protegidas por el derecho de autor (IPDA), que representan en la actualidad aproximadamente más de un 3.3\% del producto interno bruto del país. ${ }^{3} \mathrm{Al}$ no existir una protección jurídica clara y definida tanto la industria como los creadores están perdiendo los incentivos para mantenerse en esta actividad y en el fomento de la producción cultural del país.

El presente trabajo tiene como objetivo analizar cuáles son los problemas que tiene el derecho de autor en Colombia, respecto a su adaptación al ámbito de las nuevas tecnologías, principalmente en los medios digitales y el Internet. Por consiguiente, se analizará la normatividad vigente sobre esta materia y la jurisprudencia relativa, haciendo un estudio riguroso del estado del arte actual; se expondrán los vacíos normativos existentes; la problemática que se ha vivido con las leyes que se han intentado implementar para cumplir con las obligaciones establecidas en el TLC con Estados Unidos; los nuevos modelos de negocio y la importancia de adaptarlos a la Ley; finalmente, se estudiarán las legislaciones de derecho comparado más relevantes en estos temas con el fin de resaltar qué aspectos podrían aplicarse de forma positiva en Colombia.

3 ORGANIZACIÓN MUNDIAL DE LA PROPIEDAD INTELECTUAL. La contribución económica de las industrias del derecho de autor y los derechos conexos en Colombia. Bogotá: oMPI, 2008. 


\section{DEFINICIONES}

\section{A. Visión general del derecho de autor y derechos conexos}

El derecho de autor protege las creaciones intelectuales artísticas, científicas o literarias susceptibles de ser divulgadas o reproducidas en cualquier forma. ${ }^{4} \mathrm{El}$ requisito esencial para gozar de dicha protección es que la creación sea original, es decir, que no se trate de una copia total o parcial de otra obra ya existente, y que suponga un esfuerzo y un trabajo de su autor.

El derecho de autor protege "exclusivamente la forma mediante la cual las ideas del autor son descritas, explicadas, ilustradas o incorporadas a las obras. No son objeto de protección las ideas contenidas en las obras literarias y artísticas, o el contenido ideológico o técnico de las obras científicas". ${ }^{5}$ La protección de dicha expresión se da en el momento en el cual se crea la obra, por tanto no es necesario ningún tipo de registro para ser sujeto del amparo del derecho de autor. Por lo anterior, el registro es opcional para el autor, puesto que es un instrumento meramente declarativo del derecho y no constitutivo.

En cuanto a los derechos sobre la obra, el derecho de autor tiene un contenido patrimonial (derecho de puesta a disposición, derecho de reproducción, derecho de comunicación al pú-

4 RENGIFO GARCÍA, Ernesto. Ob. cit., p. 40

5 COMUNIDAD ANDINA DE NACIONES. Decisión 351 de 1993, artículo 7. blico, derecho de transformación y derecho de seguimiento o Droit de suite) y uno moral (derecho a la paternidad de la obra, derecho a la integridad de la obra, derecho de modificación sobre la obra, derecho de retiro y derecho de mantenerla inédita). El primero (derecho patrimonial) se refiere a la facultad que tiene el creador de explotar económicamente su obra, mientras que los derechos extra patrimoniales se refieren al poder de control que el autor tiene sobre su creación.

Finalmente, los derechos conexos tienen que ver con la protección que se les otorga a los intérpretes o ejecutantes de la obra, productores de fonogramas y organismos de radiodifusión. Los derechos de que gozan los anteriores actores se refieren a la capacidad de "autorizar o prohibir la comunicación al público en cualquier forma de sus interpretaciones y ejecuciones no fijadas, así como la fijación y la reproducción de sus interpretaciones o ejecuciones". ${ }^{6}$

\section{B. Ámbito digital}

Teniendo en cuenta que el presente trabajo pretende realizar un análisis de la situación del derecho de autor en el ámbito digital, es importante hacer ciertas precisiones sobre el mundo digital.

La tecnología digital permite la transmisión y el uso de todos los materiales protegidos por la ley de derechos de autor, en forma digital, a través de redes interactivas. El proceso de "digitaliza- 
ción" consiste en la conversión de materiales a una forma binaria para poderlos transmitir a través de Internet, y con ello la posibilidad de redistribuirlos, copiarlos y almacenarlos en forma digital. De este modo, se puede decir que la digitalización es el proceso técnico que logra la conversión de signos convencionales en digitales, y hace posible que estos sean leídos y procesados como datos, que se muestran con palabras, sonidos, imágenes y video. ${ }^{7}$

Cuando una obra está digitalizada se puede reproducir de forma masiva, así como también alterarse y transformarse, muchas veces sin tener en cuenta los derechos que el autor posee sobre ella. "La teoría clásica del derecho de autor continúa aplicándose y es allí donde se encuentra la primera dificultad al tratar el tema del derecho de autor en el entorno digital: la falta de legislación tanto nacional como internacional respecto de la protección de las obras frente a las nuevas tecnologías de información y comunicación (TIC)". 8

Existen dos tipos de obras digitales: las interactivas y las no interactivas. Estas últimas hacen referencia a aquellas que se muestran en la pantalla del ordenador, de principio a fin, en forma lineal. En contraste, las obras interactivas permiten escoger dentro de una variedad de opciones para cambiar los contenidos ejecutados por el computador.

7 ANTEQUERA PARILLI, Ricardo. El derecho de autor en el entorno digital. En: Revista de Derecho Privado, diciembre de 2002, vol. 16, n. ${ }^{\circ}$ 29, p. $1-35$.

8 TOBÓN FRANCO, Natalia y VARELA PEZZANO, Eduardo. Derechos de autor para creativos. Bogotá: Grupo Editorial Ibáñez, 2010, p. 38.
Aspectos importantes que se deben resaltar del medio digital son: la fidelidad de los datos incorporados, la alta velocidad de respuesta y la posibilidad de almacenar grandes cantidades de información. Así mismo, la tecnología digital posibilita una fácil difusión de la información mediante la transmisión y recepción de datos, por lo cual tanto la oferta de bienes y servicios como la adquisición de estos a través de operaciones financieras en línea han generado una nueva forma de comercio, denominada comercio electrónico. ${ }^{9}$

El Diccionario de la Real Academia de la Lengua Española define Internet como una "Red informática mundial, descentralizada, formada por la conexión directa entre computadoras u ordenadores mediante un protocolo especial de comunicación". Dentro de los datos que se transmiten por Internet se encuentran las obras protegidas por el derecho de autor, luego de ser sometidas al proceso de digitalización, y por ende su comercialización. El problema surge cuando personas o empresas inescrupulosas realizan, sin autorización, los derechos patrimoniales exclusivos del autor como son: 1) la reproducción, 2) la distribución, 3) la comunicación pública y 4) la transformación de una obra, afectando igualmente los derechos morales y conexos.

Desde la perspectiva de los derechos de autor, el Internet ha sido descrito como "la máquina de copia más grande del mundo", ${ }^{10}$ porque supe-

\footnotetext{
$9 \quad$ Ibídem.

10 LAUREN GIBBONS, Paul. Current copyright law doesn't adequately cover the Internet. En: PC Week, 27 de enero de 1997. Disponible en: http://www.securityonline.com/info/pcweek.html Consultado el 9 de
} 
ra notablemente los métodos tradicionales de reproducción como la fotocopia y la grabación, que permiten a los consumidores individuales la copia mecánica de textos en un tiempo mayor al demandado por Internet, y requieren además que los ejemplares se encuentren de forma física en el mismo lugar en que está la persona que hace la copia.

En Internet, por el contrario, se puede realizar un número ilimitado de copias, casi instantáneamente, sin degradación perceptible de la calidad, y ponerlas a disposición del público en distintos lugares del mundo en cuestión de minutos. El resultado ha sido la disminución de los mercados tradicionales y la irrupción de negocios dedicados a la venta de copias de los programas, arte, libros, películas, entre otros. En la industria de la música, por ejemplo, la aparición de plataformas basadas en el intercambio de servicios como Napster y otras, han permitido la explotación a gran escala de música y grabaciones sin la autorización de los titulares de derechos. ${ }^{11}$

Cada una de las páginas web puede ser una combinación de obras literarias, musicales, teatrales, audiovisuales, multimedia, etc., vinculadas a través de enlaces (links) que funcionan con un protocolo conocido como HTTP (Hyper Text Transfer Protocol). ${ }^{12}$ Algunas estadísticas que

mayo de 2011

11 Ibídem.

12 Ibídem. reflejan la importancia y el impacto del Internet a nivel mundial revelan las siguientes cifras: ${ }^{13}$

Usuarios de Internet: 1.463,632,361 personas usan Internet en todo el mundo, si usted solo vende al $1 \%$ de ese mercado tendría alrededor de 15 millones de ventas.

Crecimiento correo electrónico: 1.3 billones de usuarios de correo electrónico en todo el mundo y 210 billones de correos electrónicos enviados por día en 2008.

Sitios web: (i) Total de sitios web en Internet en diciembre de 2008: 186.727.854; (ii) Total de sitios web agregados a Internet en 2008: 31.5 miIlones; (iii) Total de blogs en 2008: 133 millones.

Dominios propios: 96.5 millones de registros de dominios .com, .org y .net.

Internet ha exigido también que los autores sean más creativos e interactivos al exponer sus obras, ya que cualquier persona puede escribir y publicar, por ejemplo en un blog, sin el costo que implica publicar la obra en físico. De igual forma, es posible divulgar videos en páginas como YouTube y canciones en redes sociales como MySpace y Facebook, que son de gran significación para la sociedad actual (Colombia es el catorceavo país con más miembros: superó los 10 millones en el $2010^{14}$ ).

13 Realizadas por la empresa de consultoría de Internet Raffamenmel. com. Disponible en: http://rafamemmel.com/2009/estadisticas-crecimiento-internet/ Consultado el 24 de mayo de 2011.

14 Estadística tomada de: http://marketing.es/estadisticas-de-uso-defacebook-por-paises/ Consultada el 24 de mayo de 2011. 
El desarrollo de las tecnologías digitales y la transmisión de obras a través de redes han planteado serios interrogantes sobre cómo se aplican los derechos de autor y derechos conexos en este nuevo entorno. Por ejemplo, ¿en Internet cuándo se entiende que se efectúa una copia y cuando una reproducción?, ¿existe comunicación al público cuando una obra no se difunde, sino simplemente se pone a disposición de personas individuales?

Si bien la Decisión Andina 351 y respectivamente la Ley 23 de 1982 no hacen una distinción específica en cuanto a los medios por los cuales pueden explotarse los derechos patrimoniales (reproducción, distribución, transformación y comunicación pública), en el entorno digital es imperativo determinar su aplicación.

1) El derecho de reproducción en el entorno digital se refiere a todo tipo de copia de la obra por un medio digital. Por lo tanto, toda grabación sonora o visual implica reproducción, basta con la simple fijación de la obra en la memoria del computador para que haya reproducción, así se trate de una reproducción transitoria en la memoria RAM del computador. Ahora bien, toda vez que esta reproducción beneficie económicamente a la persona que la realiza y se genere un perjuicio al titular del derecho de autor, se entenderá que se están infringiendo sus derechos patrimoniales, incluyendo el de reproducción. ${ }^{15}$ Para hacer uso de una obra protegida por el de-

15 RICO CARRILO, Mariana. Derecho de las nuevas tecnologías. Buenos Aires: Roca Editorial, 2007, p. 446. recho de autor se debe contar con la autorización previa de su creador.

La aplicación adecuada del derecho de reproducción, en el caso de las copias temporales en la memoria de los computadores de acceso aleatorio (RAM), sigue siendo un tema de debate en el plano internacional. La pregunta clave es si las copias siempre requieren el consentimiento del titular de derechos con el fin de evitar la infracción. Sobre este punto se ha estudiado la posibilidad de crear ciertas excepciones. Por ejemplo, en los Estados Unidos de América se promulgó la Digital Millennium Copyright Act (DMCA $)^{16}$ y la Comunidad Europea aprobó la Directiva sobre la armonización de determinados aspectos de los derechos de autor y derechos afines en la sociedad de la información (Directiva Europea de propiedad intelectual), ${ }^{17}$ con ciertos criterios para determinar cuándo una reproducción es ilegal y cuándo es legítima.

Respecto al derecho de reproducción en el ámbito digital, la Declaración concertada sobre el artículo 1.4 del TODA señala:

El derecho de reproducción, tal como se establece en el Artículo 9 del Convenio de Berna, y las excepciones permitidas en virtud del mismo son totalmente aplicables en el entorno digital, en particular a la utilización de obras en forma digital. Queda entendido que el al-

16 Digital Millennium Copyright Act, Title II, Pub. L. No. 105-304, 112 Stat. 2860 (1998).

17 WORLD INTELLECTUAL PROPERTY ORGANIZATION. The Impact of Internet on Intellectual Property Law. Introduction to digital copyright. Disponible en: http://www.wipo.int/copyright/en/ecommerce/ ip_survey/chap3.html\#_ftn66 Consultada el 9 de mayo de 2011. 
macenamiento en forma digital en un soporte electrónico de una obra protegida, constituye una reproducción en el sentido del artículo 9 del Convenio de Berna.

2) Respecto del derecho de comunicación al público. En el entorno digital existe un sinnúmero de formas de comunicación al público, como el "streaming on demand" (caso YouTube), las emisoras digitales, entre otros medios que tendrían la obligación de pagar una tarifa, como se hace cuando la comunicación se realiza por medios tradicionales.

Este tipo de transmisión se diferencia de la radiodifusión, toda vez que el material no es seleccionado y emitido por un transmisor activo, como un organismo de radiodifusión, a un grupo de receptores pasivos. Por el contrario, se transmite de forma interactiva, es decir, a los usuarios individuales, en el momento y el lugar de su elección.

De este modo, la comunicación pública en los medios digitales y el Internet ha tenido otra modalidad de explotación de la obra, que ha sido denominada por un amplio sector doctrinario como "puesta a disposición". Esta vertiente del derecho de comunicación pública implica que los titulares de los derechos de autor puedan limitar el derecho de puesta a disposición y obtener un recaudo por tal concepto.

La puesta a disposición se da cuando una persona sube a una página web un contenido protegido y el dueño de un dominio de Internet permite la disposición del mismo. Este derecho de comunicación pública debe estar autorizado por el titular de la obra y debe ser entendido como una especie de distribución pero en el ámbito digital. ${ }^{18}$ Un ejemplo de esto lo encontramos en las tiendas en línea que dejan reproducir un avance de la canción, para que el comprador la conozca y decida si la compra o no. De este modo, el servidor que ofrece este servicio está ejerciendo el derecho de puesta a disposición, autorizado por el titular del derecho. Se trata de un sistema de mutua compensación: el titular del derecho autoriza la exposición de su obra y decide si esta acción debe ser remunerada o no.

El TODA (artículo 8) y el tolef (artículo 14) también aclaran el grado de control de los titulares de derechos sobre las obras, interpretaciones 0 ejecuciones y fonogramas que se ponen a disposición del público para su descarga o acceso en Internet.

Los productores de fonogramas gozarán del derecho exclusivo de autorizar la puesta a disposición al público de sus fonogramas, por medios alámbricos o inalámbricos, de tal manera que los miembros del público puedan acceder a ellas desde el lugar y en el momento que cada uno de ellos elija. Dejando a cada país decidir la forma de categorizar este derecho en virtud del derecho nacional. ${ }^{19}$

\section{En cuanto al derecho de distribución en el} entorno digital es preciso preguntarse si el almacenamiento de datos en la memoria RAm del computador, además de ser una reproducción,

\footnotetext{
18 RICO CARRILO, Mariliana. Ob. cit., p. 450, 451.

19 WORLD INTELLECTUAL PROPERTY ORGANIZATION. Ob. cit., artículo 14.
} 
también representa una distribución de ejemplares de la obra. Al respecto, cabe aclarar que este tema fue objeto de gran número de debates, los cuales terminaron plasmados en los artículos 6 y 7 del TODA, en donde se concluyó que el derecho de distribución debía limitarse a la distribución de copias físicas y tangibles:

tal como se utilizan en estos artículos las expresiones copias originales y copias sujetas al derecho de distribución y al derecho de alquiler en virtud de dichos artículos, se refieren exclusivamente a las copias fijadas que se pueden poner en circulación como objetos tangibles (en esta declaración concertada, la referencia a copias debe ser entendida como una referencia a ejemplares, expresión utilizada en los artículos mencionados). ${ }^{20}$

Finalmente, en cuanto a los derechos morales de los autores y de los intérpretes y ejecutantes, estos deben protegerse de igual manera en el entorno digital, otorgándoles un margen restrictivo en los casos en los cuales las modificaciones sean inherentes a la tecnología utilizada. La protección de los derechos morales debe garantizarse no solo para conseguir una indemnización a los perjuicios ocasionados al titular del derecho, sino también para que no continúe su vulneración, y se rectifique en determinado caso frente a cualquier daño que se le pueda haber causado.

Después de esta síntesis básica del derecho de autor y el ámbito digital, a continuación se

20 ORGANIZACIÓN MUNDIAL DE LA PROPIEDAD INTELECTUAL. Declaración concertada respecto de los artículos 6 y 7 del Tratado de la OMPI sobre Derecho de Autor (TODA). expondrá la situación actual en Colombia de la protección de los derechos de autor y las nuevas tecnologías.

\section{SITUACIÓN ACTUAL DEL DERECHO DE AUTOR EN COLOMBIA}

Colombia, al ser un país en vía de desarrollo, debe usar la protección legal de los derechos de propiedad intelectual como impulso cultural de su pueblo, puesto que se trata de un estímulo y una compensación al esfuerzo creativo que fomenta su desarrollo intelectual. A continuación se expone el marco normativo que rige en Colombia.

\section{A. Ámbito internacional}

\section{Convenio de Berna para la Protección de las Obras Literarias y Artísticas}

Este tratado fue "aprobado en Colombia por la Ley 33 de 1987. El Convenio de Berna fue adoptado en 1886 y posteriormente revisado y completado, hasta 1971 en París. Contiene una serie de disposiciones que determinan la protección mínima que ha de conferirse a los autores sobre sus obras literarias y artísticas y se funda en los principios de trato nacional, de protección automática y de independencia de la protección". ${ }^{21}$

El Convenio contiene regulaciones sobre obras que están protegidas por el derecho de autor,

21 Ibídem 
los titulares de los derechos, las condiciones de la protección, los derechos protegidos, las limitaciones a la protección, la vigencia de la protección y la posibilidad para las partes contratantes de realizar reservas a ciertas normas en él estipuladas.

Este Convenio fue creado por los países de la Unión Europea con el fin de proteger de modo más eficaz y uniforme los derechos de los autores sobre sus obras. Es el tratado base de los derechos de autor internacionalmente, pero debido a su antigüedad no incluye aspectos importantes como los derechos conexos (que fueron desarrollados posteriormente por la Convención de Roma) y la protección de las obras en medios digitales.

\section{Convención de Roma}

Esta Convención fue incorporada a la legislación colombiana por medio de la Ley 48 de 1975 y es la base de los derechos exclusivos de los titulares de los derechos conexos. Protege los derechos de los intérpretes, ejecutantes, productores de fonogramas y de los organismos de radiodifusión que son quienes ayudan a la realización de la obra.

\section{Convenio para la Protección de los Productores de Fonogramas}

Este Convenio fue firmado en Ginebra en 1971 y aprobado en Colombia por la Ley 23 de 1992. El objeto principal es proteger a los productores de fonogramas de cada Estado contratante contra la reproducción de copias con miras a la distribución pública, sin el consentimiento del productor.

El Convenio da una protección muy general a los productores de fonogramas, ya que pone a discreción de cada Estado adoptar las disposiciones que considere más benéficas para sus ciudadanos. Al igual que los dos convenios anteriores, no delimita como tal el ámbito digital sino que de manera amplia habla de las restricciones a la distribución de fonogramas, sin especificar el medio de difusión.

\section{Acuerdo sobre los Aspectos de los De- rechos de la Propiedad Intelectual rela- cionados con el Comercio (ADPIC)}

Por medio de la Ley 170 de 1994 se aprueba en Colombia este acuerdo multilateral, del cual hacen partes todos los países miembros de la Organización Mundial del Comercio (омc). La omc fue el resultado de las negociaciones comerciales de la Ronda Uruguay, en el marco del Acuerdo General sobre Comercio y AranceIes (GATT). El Acuerdo sobre los ADPIC es conocido como el anexo $1 \mathrm{C}$ del acuerdo que estableció la омc. Se caracteriza porque incorporó dentro de su contenido las disposiciones del Convenio de Berna, artículos 1 al 21, excluyendo el artículo 6 Bis sobre los derechos morales. Todas las disposiciones que estén dentro de los citados artículos deben aplicarse pero siempre evitando la creación de obstáculos al comercio. Dentro de él se establece que los países miembros deben especificar que los programas de ordenador también están protegidos como obras literarias, y también se deben proteger 
las compilaciones de datos como creaciones intelectuales.

A diferencia de los anteriores convenios, este Acuerdo involucra el ámbito digital. Además de incorporar los programas de ordenador y las compilaciones de datos, menciona el tema de la difusión por medios inalámbricos por ser un medio para la protección de las obras literarias y artísticas en los medios digitales, lo que trae como consecuencia que tanto los autores como aquellos que ayudan a la creación de la obra cuenten con más herramientas para la protección de sus derechos.

\section{Tratados de la OMPI sobre Derecho de Autor (TODA) y sobre Interpretación o Eje- cución y Fonogramas (TOIEF)}

El TODA fue adoptado el 20 de diciembre de 1996 en Ginebra y tiene como propósito la protección de los autores, la introducción de nuevas formas internacionales y dar soluciones a los nuevos retos e interrogantes que trae consigo la tecnología de "la información y la comunicación en la creación y utilización de obras, particularmente en el denominado entorno digital. ${ }^{22}$

En este tratado se protegen los programas de ordenador y las compilaciones de datos. Así mismo, se prohíbe la difusión de las obras sin autorización por medios alámbricos e inalámbricos. Como complemento a lo anterior, en el artículo 11 se mencionan las obligaciones relativas a las medidas tecnológicas y se establece que las

22 Ibídem. partes contratantes proporcionarán protección jurídica adecuada y recursos jurídicos efectivos contra elusión de las medidas tecnológicas utilizadas por los autores en relación con el ejercicio de sus derechos. En el artículo 12 se habla de las obligaciones relativas a la información sobre la gestión de derechos y se mencionan elementos como información electrónica, directamente relacionada con los medios digitales.

Por su parte, el tolef fue adoptado en Ginebra el 20 de diciembre de 1996. Su propósito fundamental es regular los derechos de propiedad intelectual de los artistas, intérpretes o ejecutantes y de los productores de fonogramas, incluyendo la protección en el entorno digital.

\section{B. Norma comunitaria}

La integración subregional de los países miembros de la Comunidad Andina de Naciones (CAN) adoptó por primera vez la creación de un régimen armónico en materia de derechos de autor y derechos conexos que se concretó en el Régimen Común sobre Derecho de Autor y Derechos Conexos, aprobado el 17 de diciembre de 1993 por medio de la Decisión Andina 351.

Las implicaciones de esta norma comunitaria son de diferente índole. En primer lugar, por el alcance que tienen las disposiciones comunitarias en nuestro ordenamiento jurídico. La suscripción del Acuerdo de Cartagena o Pacto Andino creado en 1967, "hace que sus miembros adquieran la obligación de adoptar las medidas necesarias para asegurar el cumplimiento de las normas comunitarias y se comprometan a 
no adoptar ni emplear medida alguna que sea contraria a dicha norma o que de algún modo obstaculice su aplicación". ${ }^{23}$

De este modo, en aplicación del bloque de constitucionalidad las normas comunitarias hacen parte de nuestro ordenamiento y no pueden contradecirse por normas internas ni por disposiciones judiciales. En este sentido, el Tribunal de Justicia del Acuerdo de Cartagena ha señalado que los países miembros

frente a la norma comunitaria, no pueden formular reservas ni desistir unilateralmente de aplicarla, ni pueden tampoco escudarse en disposiciones vigentes o en prácticas usuales de su orden interno para justificar el incumplimiento o la alteración de obligaciones resultantes del derecho comunitario. No debe olvidarse que en la integración regida por las normas del ordenamiento jurídico andino, los Países Miembros están comprometidos a no adoptar ni emplear medida alguna que sea contraria a dichas normas o que de algún modo obstaculice su aplicación. ${ }^{24}$

Es importante resaltar que la can, con el fin de fomentar las relaciones comerciales mediante el uso de medios digitales, suscribió el Documento de Lima sobre la Sociedad Global de la Información, en el cual convienen, además de constituir como objetivo común el garantizar el acceso de la población a los servicios de tele-

23 RUBIO TORRES, Jaime Felipe. La aplicabilidad de las disposiciones comunitarias andinas en materia de derecho de autor y derechos conexos.

24

TRIBUNAL DE JUSTICIA DEL ACUERDO DE CARTAGENA. Sentencia 2-IP-88. comunicaciones, establecer normas que doten de seguridad las diferentes fases de las operaciones comerciales que utilizan recursos electrónicos, entre ellas el pedido, la contratación, el pago, la entrega, la devolución, así como la verificación de firmas electrónicas y la constitución de entidades de certificación. Con ello se buscaba propiciar una tendencia regional hacia el crecimiento en el campo de los negocios mediante las nuevas tecnologías, donde sin duda los negocios relacionados con los derechos de autor crecerían en los medios electrónicos, con lo cual aumentaría la necesidad de regularlos. ${ }^{25}$

\section{C. Ámbito nacional}

\section{Constitución de 1991}

La protección de la propiedad intelectual en la Carta Política se encuentra contenida en los artículos 61 y 71. Ambos hacen referencia principalmente a la protección y al incentivo de la propiedad intelectual en el Estado colombiano, y a su importancia al ser elevados a un rango constitucional. Sin embargo, ninguna de estas normas especifica qué se entiende por propiedad intelectual ni qué derechos comprende.

\section{Código Civil colombiano}

El artículo 671 del Código Civil expresa lo siguiente: “Artículo 671. Las producciones del talento o del ingenio son una propiedad de sus

HERNÁNDEZ MARTíNEZ, William David. La contratación por medios electrónicos en el marco de la Comunidad Andina. Estado del arte. En: Civilizar, julio-diciembre de 2009, vol. 9, n. 17, p. 89-116. 
autores. Esta especie de propiedad se regirá por leyes especiales".

Para el legislador colombiano, quien genera producciones de talento o ingenio adquiere sobre ellas un derecho de propiedad para usar, gozar y disponer de dichas producciones, que puede asimilarse al derecho real pero refiriéndose a bienes incorporales. Sin embargo, como se puede evidenciar, la norma citada es muy amplia y se limita a remitir la regulación de los derechos de autor a normas especiales, las cuales se especifican a continuación.

\section{Ley 23 de 1982}

Esta Ley contiene las disposiciones generales y especiales que regulan la protección de los derechos de autor en Colombia. "Fue el estatuto básico de los derechos de autor y conexos, el cual hoy complementa, a través de normas de reenvío, las disposiciones de la Decisión 351 de 1993: Régimen Común Andino en materia de Derechos de Autor y Derechos Conexos". ${ }^{26}$

En ella se presentan algunos vacíos respecto de la protección de los derechos de autor frente a las nuevas tecnologías, ya que no incluye la protección de producciones contenidas en dispositivos y medios de grabación digitales, descargas por Internet, manejos de bases de datos, protección de software, entre otros. Sin embargo, cabe resaltar que en su artículo 2 se expresa que la protección de los derechos de autor existirá en

26 DIRECCIÓN NACIONAL DE DERECHOS DE AUTOR. Derecho de autor y derechos conexos en Colombia. Aspectos normativos. Bogotá: Convenio Antipiratería para Colombia, 2004, p. 105. todos los medios conocidos o por conocer, que puedan servir de soporte de la obra.

Del mismo modo, el artículo 3 literal b, le otorga las facultades al creador o a quien ostente la titularidad de los derechos patrimoniales de la obra, para aprovecharla o restringir su uso con fines de lucro por cualquier medio conocido o por conocer, de manera tal que interpretando estas normas en un sentido amplio serían aplicables a los medios digitales.

Sobre este punto es importante reiterar que en la actualidad el negocio que involucra los derechos de autor está en un proceso de cambio constante, debido a que con el Internet se ha creado un nuevo mercado que necesita una regulación específica que, desafortunadamente, la Ley 23 de 1982 no contempla por su antigüedad.

\section{Ley 44 de 1993}

Esta Ley modifica la Ley 23 de 1982 y contiene disposiciones relacionadas con el Registro $\mathrm{Na}$ cional de Derecho de Autor, con las sociedades de gestión colectiva de derechos de autor y derechos conexos, así como disposiciones penales sobre el tema.

Aunque la Ley 44 de 1993 modifica y adiciona disposiciones de la Ley 23 de 1982, no incluyó regulaciones relacionadas con las obras y creaciones expresadas en medios digitales, basándose principalmente en medidas sobre gestión colectiva. 


\section{Ley 599 de 2000 y Ley 906 de 2004}

El Título VIII de la Ley 599 por la cual se expide el Código Penal colombiano, en los artículos 270, 271 y 272 contiene los delitos relacionados con los derechos de autor. El artículo 270 habla sobre la violación de los derechos morales del autor; el artículo 271 se refiere a la violación de los derechos patrimoniales y derechos conexos y el artículo 272 trata sobre la violación a los mecanismos de protección del derecho de autor y derechos conexos y otras defraudaciones.

La protección de que trata el artículo 271 es muy general, sin embargo, dado que en Colombia aún no se ha expedido una reglamentación específica sobre esta materia, se puede deducir que las obras en medios digitales también están protegidas por esta legislación. En el artículo 272 se incluyen las medidas tecnológicas y la gestión electrónica de derechos pero no se refiere específicamente a los mecanismos de protección de obras en medios digitales.

Por su parte, en el artículo 315 del Código de Procedimiento Penal (Ley 906 de 2004), establece que los delitos relacionados con los derechos de autor no son privativos de la libertad.

\section{TLC Colombia - Estados Unidos}

Finalmente, vale la pena resaltar el tratado de libre comercio firmado entre Colombia y Estados Unidos, en el cual nuestro país se comprometió a realizar una serie de modificaciones en el ámbito de la propiedad intelectual. El Capítulo 16 del texto final del acuerdo determina, en mate- ria de derechos de autor, que las partes deben propender por el equilibrio entre el derecho de autor en el medio digital y el acceso a la cultura e información de la población.

Para cumplir con los objetivos del TLc, el gobierno colombiano propuso el Proyecto de ley 241 de 2011 "Por la cual se regula la responsabilidad por las infracciones al derecho de autor y los derechos conexos en internet", que alcanzó a ser presentada como Ley Lleras.

Con ella se buscaba principalmente adoptar un mecanismo ágil para eliminar de Internet obras protegidas por el derecho de autor. Así mismo, establecía que ante una infracción, el titular de derechos de autor reclamaría ante el proveedor de servicios de Internet para que este se pronunciara sobre la infracción, y obligaba al proveedor a incluir en el contrato cláusulas para regular la terminación de este a infractores reincidentes. Si el proveedor consideraba que existía una infracción tenía la potestad de retirar o bloquear el contenido infractor.

El texto del proyecto de ley generó mucha controversia porque se entendió como una contraposición al derecho de los internautas a acceder a la información y a la libertad de expresión. Finalmente no fue aprobado por el Congreso.

Posteriormente, se presentó un segundo proyecto de ley con algunas modificaciones. Desafortunadamente, esta Ley fue declarada inexequible por la Corte Constitucional por las siguientes razones: 
(i) el primero por cuestiones de forma, ya que dicha ley fue discutida en las comisiones primeras y no en las comisiones segundas como debía ser; (ii) en segundo lugar, la Corte Constitucional consideró que prohibir y/o sancionar que se transmita la señal de televisión por Internet sin autorización del titular de los derechos constituye una violación al derecho de acceder a la información de forma gratuita y evita que el consumidor pueda obtener información de diferentes fuentes y que obtenga una información verídica e imparcial; y (iii) la Corte Constitucional consideró que este proyecto vulnera el derecho a la educación y a la cultura, pues impediría el libre acceso a diversos contenidos disponibles en línea, como libros o artículos. ${ }^{27}$

Ante el fracaso de los dos proyectos anteriores, el 17 de mayo de 2013 se presentó un tercer proyecto de ley relacionado con derechos de autor. Su contenido es muy parecido al de la ley 1520 aunque contiene ciertas modificaciones como, por ejemplo, la supresión total del primer artículo, la modificación integral de los artículos segundo y décimo, la inclusión de nuevos tipos penales, la retransmisión a través de Internet de señales de televisión, el almacenamiento temporal de la información protegida que se descargue de la red y el uso de esta información para fines no comerciales.

Al respecto hay que anotar que el afán del gobierno por regular los derechos de autor para cumplir el compromiso adquirido al firmar el TLC con Estados Unidos, ha impedido revisar dete-

27 VELAZCO ORDOÑEZ ABOGADOS. Nuevamente, la mal llamada "Ley Lleras". Disponible en: http://velasco.com.co/nuevamente-la-malIlamada-ley-lleras/ nidamente el tema de la regulación y se están proponiendo medidas muy drásticas para los usuarios de Internet, con las que no solo se les vulneraría el derecho a la información y a la libre expresión, sino que se pierde de vista que si bien hay que prevenir infracciones no se puede limitar y violentar el derecho de un tercero.

Lo anterior demuestra que la regulación actual no es suficiente para proteger los derechos de autor en Internet y que es preciso hacer un análisis profundo desde el punto de vista del autor y de los consumidores, con el ánimo de lograr una legislación equitativa y justa que garantice la protección efectiva que se busca.

\section{FORMAS DEL NEGOCIO DIGITAL}

Después de haber analizado el marco jurídico de los derechos de autor en Colombia, es importante definir las modalidades del negocio digital y la forma en que el derecho de autor puede incidir en estas, con el fin de determinar las falencias que existen en nuestro ordenamiento con respecto a la regulación de dichos negocios.

Los derechos de autor ligados con el negocio del entretenimiento generaron un valor agregado bruto (VAB) al total de las IPDA, de $\$ 9.5$ billones en el año 2005 y $\$ 5.7$ billones en el 2000, representando un $3.3 \%$ del PIB. ${ }^{28}$

Al hacer una comparación tangible de la participación de la industria del entretenimiento con contribución... Ob. cit. 
respecto a las demás, encontramos que durante el período analizado las IPDA tuvieron una participación en el PIB similar al del sector de la electricidad y gas, y más del doble que la de café y carbón, lo que resulta significativo teniendo en cuenta que tradicionalmente Colombia ha mantenido una alta participación mundial en estos dos productos. $^{29}$

En materia de empleo, las IPDA en el 2006 generaron 1.097.430 empleos que representaron el $5.8 \%$ de la población ocupada del país y el $12.7 \%$ de las 13 grandes ciudades que lo conforman, cifras que demuestran la incidencia de estas industrias en el empleo nacional. ${ }^{30}$

En la actualidad, el negocio del entretenimiento ha cambiado sustancialmente, debido a las tiendas de descargas de música, video, multimedia y libros por Internet, las cuales han generado nuevas formas de mercado que no se encuentran debidamente reguladas.

\section{A. Medios en los que se explota el negocio digital}

Mediante la utilización de Internet es posible realizar varias transacciones en el marco del comercio electrónico directo e indirecto. Estos negocios operan mediante diversos contratos atípicos y bajo las más variadas formas, generando nuevas modalidades de explotación. Los siguientes son los medios relacionados más directamente con el negocio digital:

\footnotetext{
29 Ibídem

30 Ibídem.
}

a) E-book: es una versión digital o electrónica de un libro. El libro electrónico es un archivo de computadora en un formato específico: PDF, MOBI, EPUB, etc. Un lector puede almacenar cientos de libros electrónicos; además son más económicos, en la medida que no necesitan el proceso de impresión tradicional.

b) Música digital: para llegar a su definición es importante analizar y definir las dos palabras que componen el concepto. "La música es el arte de organizar en forma sensible y lógica una combinación coherente de sonidos y silencios. Los sistemas digitales, por su parte, utilizan la lógica de dos estados representados por dos niveles de tensión eléctrica que, por abstracción, se sustituyen por ceros y unos (para poder aplicar la lógica y la aritmética binaria)". ${ }^{31}$ En este orden de ideas, se puede afirmar que la música digital hace referencia a la posibilidad de convertir sonidos en números binarios. El método que se lleva a cabo para realizar dicho proceso es conocido como PCM (Pulse - Code Modulation).

c) Base de datos: es definida como el conjunto de información que está almacenada en forma sistemática, de manera tal que los datos que la conforman puedan ser utilizados en fragmentos cuando sea necesario. Los datos, organizados y relacionados entre sí, se caracterizan por la existencia de una independencia lógica y física, y por la capacidad

\footnotetext{
31 Tomado de: http://webcache.googleusercontent.com/search?q=cache :b86Bjgi8a6EJ:musicadigital2010.blogspot.com/2010_09_01_archive. $\mathrm{html}+$ definicion+musica+digital\&cd=17\&hl=es\&ct=clnk\&source=www. google.com
} 
de acceso concurrente por parte de múltiples usuarios.

d) Video: es un sistema de grabación y de reproducción de imágenes que pueden estar acompañadas de sonidos. En la actualidad los videos se pueden ver en distintos formatos como DVD y MPEG-4, entre otros. Por su parte, el videoclip, que es un video de poca duración, generalmente relacionado con el mundo de la música, es utilizado por muchos artistas para promocionar sus canciones. Con el auge de Internet y sitios web como YouTube, los video-clip se han popularizado en forma de videos musicales, fragmentos de programas de televisión, avances de películas y contenidos grabados por cualquier persona.

e) Película: es una obra de arte cinematográfica que presenta una historia de manera audiovisual, por medio de una secuencia de imágenes, con o sin sonidos, y que por lo general se basa en un guión en el que los personajes pueden o no ser interpretados por actores. En los últimos años se han venido utilizando de forma creciente soportes magnéticos y digitales para grabar películas. Con la entrada del Internet, plataformas como YouTube han permitido que miles de usuarios produzcan sus propias películas y las suban a la red. Esto explica la amplia variedad de géneros, calidad, técnicas y gustos cinematográficos que se encuentran.

\section{B. Explotación en línea de industrias protegidas por el derecho de autor}

La explotación en línea ha sido entendida como el proceso por el cual las obras protegidas por el derecho de autor y por los derechos conexos se usufructúan mediante diferentes recursos, dentro de los cuales los más utilizados son:

1) El preview, que permite tener un acceso previo a la obra, por ejemplo, la posibilidad de escuchar un pequeño fragmento de una canción, o leer algunas páginas de un libro, para que el posible comprador decida si la descarga al disco duro de su computador. ${ }^{32}$

2) El streaming ofrece al usuario de Internet la posibilidad de acceder a una obra pero no le permite fijarla en la memoria del computador. Se trata de una reproducción en tiempo real, a medida que se transmite. Normalmente el streaming se utiliza con archivos de música o de obras audiovisuales. El servidor es quien permite que el acceso a la obra sea permanente o temporal.

3) El webcasting: es una transmisión que se realiza de forma exclusiva por Internet, en el momento en que decida el servidor. El usuario ni escoge el momento en que desea tener acceso a la obra ni puede realizar ninguna descarga.

4) El simulcasting: es la retransmisión por Internet de una transmisión radial o televisiva en

32 LIPSZYC, Delia. Nuevos temas de derecho de autor y derechos conexos. Buenos Aires: Zavalía, 2004, p. 329. 
medios análogos, con algunos segundos de diferencia entre una y otra. ${ }^{33}$

\section{Nuevas creaciones en el entorno digital}

La tecnología digital ha permitido que los autores realicen nuevas obras exclusivamente para el entorno digital. Dentro de esta modalidad se pueden destacar:

1. Las obras en multimedia, producidas mediante "un programa de ordenador que incluye texto, gráficos, sonido y video en formato digital". ${ }^{34}$ El Diccionario jurídico de los medios de comunicación las define como "una obra fruto de la combinación de datos y obras de diferente tipo como texto, sonido o imagen y programas informáticos". Algunos ejemplos de obras multimedia pueden ser los video-juegos y los simuladores de vuelo.

2. El software, más conocido como programas de ordenador. Es definido por el Diccionario de la Real Academia de la Lengua Española como "un conjunto de programas, instrucciones y reglas informáticas para ejecutar ciertas tareas en una computadora". Lo que en realidad protege un programa de ordenador es el código, es decir, "el lenguaje de programación escrito por

33 Ibídem, p. 329.

34 FITZGERALD, Anne y CIFUENTES, Christine. Accomodating Computer Software to Copyright Doctrine: Defining the Scope of Copyright Protection for Software. En: Journal of Law, Information and Science. 2000-2001, vol. 11, n. ${ }^{\circ}$ 2.p. 23. una persona natural (obra literaria) para ser procesado por una computadora". ${ }^{35}$

En la Decisión 351 de 1993 de la Comunidad Andina, los programas de ordenador se protegen bajo los mismos términos que las obras literarias, por tanto el autor de un software podrá gozar y disponer de sus derechos patrimoniales igual que el autor de una obra literaria.

3) Las bases de datos: son "recopilaciones de obras, de datos o de otros elementos independientes dispuestos de manera sistemática o metódica y accesibles individualmente por medios electrónicos o de otra forma. ${ }^{36}$ Frente a este tema hay que aclarar que lo que se protege es el contenido de la base de datos y no la información como tal, ya que esta se podría encontrar en el dominio público.

4) Las obras generadas por computador: son aquellas en las cuales el ser humano solo se limita a darle órdenes a la máquina para que esta cumpla la función de crear las obras.

Este tipo de obras han generado controversia respecto a si están o no protegidas por el derecho de autor. Algunos argumentan que las máquinas no son sujetos de derechos; sin embargo, otros afirman que sí hay lugar a algún tipo de protección pues muchas de las obras cumplen con el requisito de originalidad exigido por las

\footnotetext{
35 TOBÓN FRANCO, Natalia y VARELA PEZZANO, Eduardo. Ob. cit., p. 309

36 PARRA TRUJILLO, Eduardo de la. El derecho sui generis sobre las bases de datos en México y la Unión Europea. En: Derecho comparado de la información. Enero-junio de 2004, n. ํㅛ._p. 101-124.
} 
leyes. "Al respecto, la doctrina propone cinco sujetos o posibles titulares del derecho de autor sobre las obras generadas por el computador: (i) El programador del programa de computador; (ii) el usuario del programa;(iii) tanto el programador como el usuario; (iv) el computador o (v) nadie". ${ }^{37}$

Lo cierto es que aún no se tiene claridad sobre quiénes son titulares del derecho de autor, pues de acuerdo con el libro Los derechos de autor para los creativos, la computadora en teoría debería reputarse titular exclusiva del derecho sobre la obra que ella misma ha generado, sin embargo, dicho supuesto contraría el principio general de que solo los humanos son sujetos del derecho de autor. Además, según Darin Glasser -en su libro Copryrights in computer - generated Works-, "el propósito del derecho de autor es estimular y promover la creación de obras originales en el campo artístico y literario, todo lo cual resultaría fútil para un ordenador". ${ }^{38}$

Al no haber claridad sobre si las obras generadas por computador son titulares de derechos, ni tampoco sobre quién es el titular de la obra, es muy difícil pensar en una legislación o normatividad relacionada con este tipo de obras.

5. Los esquemas de circuitos de trazados integrados: son otro tipo de obras digitales. "El circuito integrado es un dispositivo en el que ciertos elementos con funciones eléctricas, como

37 TOBÓN FRANCO, Natalia y VARELA PEZZANO, Eduardo. Ob. cit., p. 316.

38 Ibídem. transistores, resistencias, condensadores, diodos, etc., están montados en un sustrato común como silicona pura. Estos componentes están conectados de manera que el circuito integrado pueda controlar la corriente eléctrica y, de esta manera, rectificarla, ampliarla, etc. De acuerdo con la función que vayan a ejecutar necesitan un orden y una disposición especial, es decir, se debe realizar un plan o diseño de los elementos que componen el circuito integrado, el cual conforma el esquema de Trazado de Circuitos Integrados". ${ }^{39}$

De acuerdo con el Tratado sobre la Propiedad Intelectual respecto de los Circuitos Integrados, celebrado en Washington el 26 de mayo de 1996, el cual es remitido por el artículo 35 del ADPIC, se establece que los esquemas de circuitos de trazados integrados pueden protegerse a través de: "(a) cualquiera de los derechos de propiedad intelectual (derecho de autor, patentes, modelos de utilidad, marcas, diseños industriales, secretos empresariales, etc.); (b) un derecho sui generis; y (c) derecho de competencia desleal". ${ }^{40}$ Este tipo de obras también es protegido por la Comunidad Andina en el artículo 87 de la Decisión 486.

39 COLOMBIA. SUPERINTENDENCIA DE INDUSTRIA Y COMERCIO. Diseños industriales. Esquema de trazado de circuitos integrados. Secretos empresariales. Bogotá: Ministerio de Comercio, Industria y Turismo, 2008, p. 38.

40 Tratado sobre la Propiedad Intelectual respecto de los Circuitos Integrados, celebrado en Washington el 26 de mayo de 1996. 


\section{Cómo se licencian los derechos patrimoniales y conexos}

Como ya se comentó, el titular del derecho patrimonial, respecto de la obra, tiene el control sobre cualquier forma de utilización de aquella; en consecuencia, está facultado para autorizar o prohibir cualquier explotación que sobre su obra se realice o pretenda realizarse.

El autor es el titular de los derechos patrimoniales sobre su obra, de manera que cualquier uso que pretenda realizarse sobre esta, como la transformación, reproducción, comunicación pública o distribución, deberá contar con la previa y expresa autorización de su creador. Ahora bien, un mecanismo adecuado para contar con la autorización del titular de derechos para hacer uso de la obra, y que resulta pertinente mencionar, es el contrato de licencia de derechos.

En esta tipología contractual, el autor o titular derivado de los derechos de una obra, el licenciante, tiene la potestad de autorizar, sin desprenderse de sus derechos, la utilización de su creación, bajo las condiciones de tiempo, modo y lugar establecidas en dicha licencia, a un licenciatario. Se aclara, sin embargo, que uno de los principios fundamentales del derecho de autor es la independencia de cada uno de los derechos, es decir: "la autorización para utilizar una creación en una modalidad de explotación no faculta para utilizarla en otra modalidad distinta" (artículo 77, Ley 23 de 1982).

Debe tenerse en cuenta que la referida autorización debe ser previa y expresa, esto es, anterior al momento en el cual se pretenda hacer uso de la obra, de tal manera que se constituya en una manifestación inequívoca de la voluntad del autor o titular de derechos, no solo sobre la autorización en sí misma sino también en cuanto al uso o usos permitidos.

Ahora bien, con el surgimiento de las tecnologías digitales es importante tener en cuenta dos factores que pueden generar grandes controversias. El primer interrogante que surge es, si es posible con un contrato de licencia ya perfeccionado explotar la obra en Internet, o si por el contrario se debe realizar un nuevo contrato. Frente a esta controversia no ha habido jurisprudencia que la resuelva, pero tal y como se encuentra redactada la ley, deberían renegociarse los términos de las licencias, con el fin de que no se tenga dudas sobre los medios en los que se piensa hacer la explotación de los derechos patrimoniales y conexos. Sobre esto volveremos cuando se analice cómo se han tratado estos temas en casos de los Estados Unidos.

El segundo factor de controversia en el uso de licencias es la falta de información que existe en Internet respecto de la legalidad del contenido que se descarga o utiliza en línea, toda vez que en muchos casos no hay claridad y son los usuarios de la Web quienes pueden verse perjudicados.

En Colombia no hay claridad ni legal ni jurisprudencial sobre este particular. Actualmente se está adelantando un proyecto de ley que les impone tanto a los proveedores de Internet como a los proveedores de contenidos cierta respon- 
sabilidad respecto al material que facilitan. Más adelante se estudiará con detalle este controversial tema.

De todos modos, es preciso remarcar que no puede pasarse por alto inscribir dichas licencias en el Registro Nacional del Derecho de Autor, como condición de publicidad y punibilidad ante terceros, ${ }^{41}$ y que para estos efectos, acorde con el parágrafo 2 del artículo 17 del Decreto 460 de 1995, los actos y contratos que no implican enajenación del derecho de autor se acreditarán allegando copia simple del documento en donde ello conste, como sería, por ejemplo, una autorización firmada por el titular de los derechos de autor, donde se pueda corroborar su manifestación inequívoca de voluntad. ${ }^{42}$

A continuación se especifica el tipo de licencias que existen en el negocio digital:

Licencias de uso: a diferencia de la cesión de derechos, en la licencia de uso no se transmite en ningún momento la titularidad del derecho de autor sobre la obra, simplemente le permite al beneficiario de la licencia utilizar la obra bajo las condiciones establecidas por el respectivo titular.

Esta licencia debe contemplar, entre otros factores, las condiciones de tiempo, el territorio, la forma singular de aprovechamiento de la obra y el medio o soporte para su difusión, razón por la cual debe ser cuidadosamente elaborada, evi-

$41 \quad$ Artículo 6 de la Ley 44 de 1993.

42 DIRECCIÓN NACIONAL DE DERECHOS DE AUTOR. Concepto jurídico n. ${ }^{\circ} 1-2001-1010$, del 11 de enero de 2011. tando de esta manera que por su indeterminación se torne en una cesión de derechos.

En ese orden de ideas, el titular del derecho de autor podrá establecer las condiciones de tiempo, modo y lugar dentro de las cuales el usuario podrá hacer uso de su creación, teniendo claro que cualquier utilización que desborde los límites impuestos por tales condiciones podrá considerarse una infracción a los derechos reconocidos al creador o titular de derechos. ${ }^{43}$

Licenciamiento de software: en el caso del software, en virtud de una licencia de uso y conforme a lo señalado en la Decisión Andina 351 de 1993, al titular de la misma le es permitido:

a. Hacer una fijación del programa en la memoria del computador (artículo 26).

b. Hacer una copia de seguridad o back up (artículo 24 literal b).

c. Hacer una adaptación del programa para su exclusiva utilización (artículo 24).

Licencias de código cerrado: a través de estas el autor autoriza determinados usos del código objeto de su creación, pero no permite que el usuario pueda tener acceso al código fuente.

Licencias del tipo freeware: autorizan el uso gratuito del código objeto, pero por regla general no posibilitan acceder al código fuente del programa. ${ }^{44}$

43 Ibídem. Concepto jurídico n. 1-2010-8227 del 1 de marzo de 2010.

44 Ibídem. Concepto Jurídico n. ${ }^{\circ}$ 1-2010-8250 del 15 de marzo de 2010. 
Licencias de software "open source" o de código abierto (software libre): permiten al usuario acceder al código fuente, modificarlo y hacer distribuciones.

Las licencias de software libre o de código abierto se relacionan con un tipo de permiso de características especiales, a través del cual su titular autoriza a los usuarios realizar ciertos usos de la obra como son:

- La libertad de usar el programa con cualquier propósito.

- La libertad de estudiar cómo funciona el programa y adaptarlo a sus necesidades.

- La libertad de distribuir copias.

- La libertad de mejorar el programa y hacer públicas las mejoras a los demás, de modo que toda la comunidad se beneficie. ${ }^{45}$

La característica fundamental del software libre reside en que su código fuente es abierto (Open Source). El usuario puede por ello tener acceso al código fuente con la facultad de realizar mejoras, estudiarlo, modificarlo, actualizarlo o adaptarlo. En este orden de ideas, las facultades de uso propias del software de código abierto son consecuencia del ejercicio de la autonomía privada de la voluntad de sus creadores. Es importante destacar que en ningún momento se involucra un concepto de renuncia, cesión de derechos patrimoniales o de dominio público. El concepto de software libre es independiente

45 Ibídem. del carácter oneroso o gratuito que involucre su adquisición; ${ }^{46}$ tampoco puede ser confundido con el software que se encuentre en el dominio público, toda vez que, como se ha venido exponiendo, esto depende de la voluntad del autor, expresada en la licencia.

\section{E. El Copyleft como alternativa frente a los derechos de autor: (licencias libres, el retorno del control a los creadores)}

El Copyleft es una idea que surgió en la década de los años 70 como una alternativa a las restricciones que imponen las normas planteadas por el derecho de autor, a la hora de hacer, modificar y distribuir copias de una obra determinada. Pretende garantizar una mayor libertad para cada receptor de una copia, o una versión derivada de un trabajo, para que pueda, a su vez, ser usada, modificada y redistribuida. ${ }^{47}$ Con el paso del tiempo pasó de limitarse al ámbito de la computación, especialmente en cuanto al software, a aplicarse a cualquier creación artística o científica protegida por el derecho de autor.

En lenguaje jurídico, el Copyleft es una licencia que garantiza el derecho a cualquier usuario de utilizar, modificar y redistribuir un programa o sus derivados, siempre que se mantengan las mismas condiciones de utilización y difusión establecidas en la licencia otorgada por el titular de los derechos de una obra.

46

RÍOS RUIZ, Wilson. La propiedad intelectual en la era de las tecnologías. Bogotá: Universidad de los Andes y Temis, 2009.

47 COPYLEFT. Disponible en: http://fundacioncopyleft.org/es/9/que-escopyleft. Consultado el 13 de mayo de 2011. 
La licencia de Copyleft la hace el autor o los titulares de derechos de la obra. El autor debe establecer expresamente las condiciones en las que se puede utilizar, modificar y redistribuir la obra, con lo cual queda claro que no implica necesariamente que la obra pueda usarse sin ninguna limitación y, por lo tanto, se puedan redistribuir cuantas copias se deseen, o modificarse de la manera en que se crea conveniente, toda vez que recae en cabeza del autor o de los titulares de derechos decidir estos parámetros, y de restringirlos como lo crean más conveniente. ${ }^{48}$

En la práctica se han dado dos formas generalizadas de aplicación del Copyleft: por un lado está una licencia que de forma expresa renuncia a todos los derechos y restricciones posibles sobre la obra, es decir, no impone al usuario ningún tipo de limitaciones, volviéndose prácticamente la obra parte del dominio público; por otro lado, están las licencias denominadas Creative Commons, que permiten a los autores establecer limitaciones en ciertas secciones de su trabajo y dejar exentas algunas partes de su creación o formas de modificación y de explotación. Existen ejemplos en los cuales se otorgan licencias que impiden el uso comercial de la obra, o que obligan a que se distinga la obra original de cualquier copia, o que impiden hacer modificaciones a la obra.

Hay que precisar, entonces, que por el hecho de existir sobre la obra una licencia Copyleft o Creative Commons, no significa que puedan violarse derechos de autor. Es importante entender que

48 Ibídem. ambos conceptos no se contraponen y que en realidad lo que se hace es respetar la voluntad del autor originario acerca de su explotación, siendo completamente acorde con las leyes de derechos de autor.

\section{F. Gestión colectiva}

La gestión colectiva en Colombia establece que los derechos concedidos en favor de los autores o titulares de obras literarias y artísticas les facultan para autorizar, de manera previa y expresa, la utilización de sus creaciones y el recaudo de las regalías que provienen de la comunicación pública de estas. Dicha atribución en los términos de los artículos 73 de la Ley 23 de 1982 y 66 de la Ley 44 de 1993 puede ser llevada a cabo de manera individual o colectiva. ${ }^{49}$

Al respecto, es preciso advertir que la gestión colectiva del derecho de autor se entiende legalmente subordinada a la constitución de una sociedad, que debe obtener por parte de la Dirección Nacional de Derecho de Autor la respectiva personería jurídica y autorización de funcionamiento, y someterse a la inspección y vigilancia sobre el desarrollo de su actividad por parte de dicha Dirección. En este sentido, la Corte Constitucional, en sentencia C-833 de 2007, manifestó lo siguiente:

si bien la Corte ha señalado que para la administración de sus derechos los titulares de derechos de autor y derechos conexos pueden acogerse a formas de asociación distintas a la

49 DIRECCIÓN NACIONAL DE DERECHOS DE AUTOR. Concepto jurídico n. ${ }^{0} 1-2011-7356$, del 11 de febrero de 2011. 
gestión colectiva, o realizar sus reclamaciones en forma individual, también ha sido expresa en puntualizar que quien quiera acceder a la modalidad de gestión prevista para las sociedades de gestión colectiva, debe acogerse a las previsiones legales sobre la materia.

En este orden de ideas, de conformidad con el artículo 25 de la Ley 44 de 1993, nuestra legislación excluye la posibilidad de que otras formas distintas a las sociedades de gestión colectiva ejerzan sus atribuciones, que se encuentran enumeradas en el artículo 13 de aquel cuerpo normativo. Bajo este entendido, al estar vigentes los artículos 45 de la Decisión Andina 351 de 1993, 13 y 25 de la Ley 44 de 1993, es evidente que las sociedades de gestión colectiva ejercen atribuciones particulares, que no se pueden predicar en favor de cualquier otro tipo de persona jurídica.

Cabe recalcar que la ley colombiana concede la posibilidad de realizar la gestión colectiva únicamente en medios de comunicación pública tradicionales, con lo cual excluye la comunicación pública en el entorno digital y su modalidad de puesta a disposición. El recaudo de la remuneración por la explotación del derecho de comunicación publica en Internet deben hacerlo los autores o titulares de forma individual.

La imposibilidad legal para realizar una gestión colectiva en Internet hace inexistente el recaudo de los derechos de comunicación pública en este medio, teniendo en cuenta que los autores o titulares de las obras normalmente no cuentan con la infraestructura y los medios para realizarlo.
La propuesta de una gestión colectiva de obras en Internet ha sido analizada por varios países y ha tenido muy buenos resultados. La Confederación Internacional de Sociedades de Autores y Compositores (CISAC) ha trabajado de manera ardua para integrar un amplio sistema internacional de representaciones, que permita licenciar en un número considerable de territorios todo el repertorio mundial de obras, con el fin de unificar los métodos de recaudo colectivo sin interferir en la administración interna de cada sociedad. ${ }^{50}$

Con este propósito, la cISAC ha desarrollado un sistema mundial de información común llamado cIs (Common Information System), con la intención de afrontar los desafíos que se han impuesto con la tecnología digital y el Internet. Delya Lipzsic ha resaltado tres ventajas que puede traer este sistema:

1) las ingentes ventajas que brinda el desarroIlo informático; 2) las enormes bases de datos electrónicas; 3) la transmisión de estos datos en línea, a fin de realizar de manera más eficaz la administración cotidiana y los intercambios de información entre las sociedades de la cISAC, a la vez que, de cara al nuevo milenio, poder llevar una gestión colectiva efectiva de la utilización de obras en el entorno digital. ${ }^{51}$

En este sentido, el cis plantea dos tipos de herramientas que pueden ser utilizadas por las sociedades de gestión colectiva alrededor del mundo, con el fin de realizar una labor efectiva.

LIPSZYC, Delia. Ob. cit., p. 333.

51 Ibídem, p. 333-334 
La primera es la asignación de identificadores internacionales únicos para cada obra y cada creador, con lo cual se pretende poder determinar si la obra fue utilizada de forma expedita, saber a quién pertenece la titularidad de los derechos patrimoniales, y si pertenece al repertorio de la CISAC, con el fin de establecer un sistema de cobro efectivo. ${ }^{52}$

La segunda herramienta es la creación de una red global de bases de datos, en las cuales se pueda depositar la información de las obras de todas las sociedades CISAC que participen en el proceso de gestión colectiva global. El propósito de la cISAC con la implementación de estas herramientas es que cada vez que se reproduzca o se ponga a disposición una obra que se encuentre en el cIs, se pueda informar automáticamente a la sociedad de gestión colectiva correspondiente, para que esta tenga información en tiempo real de la utilización de la obra y pueda realizar el cobro y recaudo de los derechos patrimoniales. ${ }^{53}$ De este modo, los autores o titulares de derechos de autor tendrán la garantía de que el recaudo por concepto de sus derechos patrimoniales por el uso de sus obras en Internet se está haciendo de manera efectiva.

Ahora bien, lo que debe hacerse en Colombia para aplicar las propuestas de la cISAC es incentivar a los titulares de derechos de autor y conexos para que presionen a las entidades de gestión colectiva a participar en el cis, de tal forma que

52 CISAC. Information networks, 12/04/07. Disponible en: http://www. cisac.org/CisacPortal/consulterArticle.do?id=269 el 16 de_mayo de 2011.

53 Ibídem puedan comenzar a gestionar ante la Dirección Nacional de Derechos de Autor la autorización para realizar el recaudo de regalías en Internet.

\section{DERECHO COMPARADO}

Por las obligaciones que Colombia adquirió con Estados Unidos en el TLC, el derecho de autor y la responsabilidad de los proveedores de Internet ha sido uno de los temas que ha cobrado mayor relevancia en los últimos años en el país. Las denominadas Ley Lleras 1 y 2 fueron proyectos de ley que tocaban el tema de la responsabilidad ante la infracción contra los derechos de autor en línea.

Este problema se produce por la propia naturaleza de las redes digitales. Cuando una obra se transmite de un punto a otro, o se pone a disposición del público por medio de una página Web, numerosas partes están involucradas en esta transmisión, una de ellas las empresas que proporcionan acceso a Internet o servicios en línea (ISP O PSO). Cuando los proveedores de tales servicios participan en la transmisión de materiales protegidos y facilitan los medios para que terceros infrinjan los derechos de autor y conexos, surge el interrogante sobre si estos debieran ser responsables solidarios de la infracción.

Ante esto, la responsabilidad de los proveedores de Internet se ha planteado de dos maneras: la primera, si el prestador de servicios realiza o participa en actos no autorizados de reproducción o comunicación al público; y segunda, si el 
proveedor del servicio se considera responsable de contribuir o hacer posible el acto de infracción por parte de otro. ${ }^{54}$

Con estos antecedentes es importante analizar, a la luz del derecho comparado, la posibilidad de implementar las disposiciones en este sentido, en el ordenamiento jurídico colombiano.

\section{A. Estados Unidos}

Uno de los principales problemas que ha venido ocurriendo en Colombia es la falta de jurisprudencia frente al tema de los derechos de autor, puesto que la rapidez con que evoluciona la tecnología ha dejado siempre al derecho atrás y hace que las legislaciones se queden cortas en su función de protección.

Es importante remarcar que los temas concernientes a los derechos de autor y conexos en Estados Unidos han sido tratados principalmente de forma jurisprudencial, porque si bien existen normas proteccionistas como la Digital Millenium Copyright Act, es evidente que el constante cambio tecnológico siempre se ha escapado de la protección legal.

En el caso The New York Times, Co. contra Tasini, la Corte Suprema de los Estados Unidos confirmó una decisión a favor de la Unión Nacional de Escritores de América, en contra de varios distribuidores de noticias que habían realizado la venta de material de escritores independientes a bases de datos electrónicas, incluyendo la

\footnotetext{
54 WORLD INTELLECTUAL PROPERTY ORGANIZATION. Ob. cit.
}

reconocida Lexis Nexis, sin que se realizara ningún pago adicional o una nueva negociación de los derechos electrónicos de los autores.

El Tribunal consideró que la re-publicación electrónica de las obras de los escritores constituía una infracción de los derechos de autor (copyright), y que los escritores tienen derecho a recibir regalías por el uso secundario que se les dé a las licencias. ${ }^{55}$ Este razonamiento fue confirmado en el caso National Geographic contra Greenberg, en el que la Corte Suprema de los Estados Unidos se negó a escuchar una apelación a una decisión anterior de la Corte de Apelaciones, la cual estableció que la reproducción de los trabajos fotográficos realizados con anterioridad para la revista National Geographic, incorporados en una colección de búsqueda de CD-ROM de ediciones pasadas de la revista implicó un nuevo uso, por lo cual los autores originales tenían derecho a recibir regalías, pues las pasadas licencias de explotación no se hacían extensibles a medios digitales. ${ }^{56}$

Ahora bien, más allá de la línea jurisprudencial de Estados Unidos, la DMCA fue la base de un esfuerzo del Congreso de dicho país para aplicar las obligaciones del TODA y para promover la ley nacional de derecho de autor a la era digital. La promulgación de la DMCa fue solo el comienzo de

55 The New York Times, Co. v. Tasini, (00-201) 206 F.3d 161; affirmed, United States District Court S.D.N.Y. 93 Civ. 8678 (SS), decided August 13, 1997. Disponible en: http://supct.law.cornell.edu/supct/ html/00-201.ZS.html. Consultado el 12 de mayo de 2011. Supreme Court of The United States, 122 S. Ct. 347; 151 L. Ed. 2d 262; 2001 U.S. LEXIS 9493; 70 U.S.L.W. 3267, October 9, 2001, decided. 
una evaluación continua por parte del Congreso sobre la relación entre cambio tecnológico y la ley de EE. UU. Si bien la DMCA generó cambios importantes en las leyes de derechos de autor en el ámbito digital y el Internet, ha sido la jurisprudencia en torno a la aplicación de esta la que ha marcado el camino hacia una protección efectiva con la incursión de las nuevas tecnologías.

\section{B. España}

En cuanto a España, se puede decir que es uno de los países más involucrados con la protección del derecho de autor, puesto que reconoce y está consciente de la importancia que tiene para su economía.

Según los últimos datos proporcionados por el Ministerio de Cultura de España, la aportación de las actividades vinculadas a la propiedad intelectual al PIB es del 3,5\%. Esta cifra supera a la de otros sectores que tradicionalmente han actuado como motores de la economía. La incidencia positiva de la propiedad intelectual en el sistema económico tiene su razón de ser en el valor que hoy tiene el conocimiento y la información para el desarrollo de cualquier actividad productiva o de investigación e innovación, y en cómo el rendimiento de lo intelectual, junto con el de las industrias culturales, contribuye a un crecimiento sostenible y sólido, alejado de modelos económicos que proporcionan un progreso efímero. ${ }^{57}$

En virtud de lo anterior, en los últimos años se creó la llamada Ley Sinde, como una forma de

57 VINENT, Magdalena. Propiedad intelectual, la razón. Disponible en: http://www.cedro.org/textos_interes_ambito_digital.asp protección adicional a los derechos de autor en el entorno digital, que complementa la Ley de Propiedad Intelectual del año 1996. Después de muchas discusiones al respecto, finalmente la Ley Sinde fue aprobada el 15 de febrero de 2011, lo cual generó una serie de reacciones negativas y críticas que llevaron a los usuarios de Internet a redactar un Manual de desobediencia de la Ley Sinde, en donde establecieron parámetros para evitar la censura que la ley promovía, dado que muchos consideraban como injusta la normatividad. Lo anterior evidencia la posición del usuario de Internet frente a la protección de los derechos de autor, en un país que supuestamente tiene una mayor conciencia sobre esta problemática pero realmente no es la más idónea.

Las mayores protestas por la Ley Sinde se basan en su supuesta censura, por considerarla directamente violatoria del derecho a la libre expresión y a la información del cibernauta. Se considera que el Estado controlará los contenidos en la red, pero la piratería continuará, tal como sucedió con la Ley HADOPI en Francia, en donde disminuyeron las descargas de contenidos punto a punto (P2P) pero se incrementó la piratería por medio de programas como MegaUpload. ${ }^{58}$

Lo que busca la Ley Sinde es regular por medio de los proveedores de servicios de Internet (PSI), los contenidos que circulan en la red y que pue-

58 TEJEIRA, Ofelia. Defensor del internauta. La Ley Sinde no es lo que parece, ahora es peor. Disponible en: http://www.internautas.org/ html/6541.html. Sobre este tema y la posición de los internautas, consultar: www.alt1040.com 
dan ser violatorios de derechos de propiedad intelectual. De esta forma los PSI, previa autorización judicial, descargarán el contenido violatorio de su página de Internet para lograr una mayor protección.

Aunque tanto la Ley Sinde como las leyes que se han intentado implementar en Colombia puedan tener muchos problemas en su constitución, se puede afirmar que constituyen un intento válido de protección de los derechos de autor, puesto que involucran un nuevo actor: el PSI. El argumento es que si bien este no está relacionado directamente con la violación de los derechos en Internet, porque no es responsable del contenido que proporcionan sus usuarios, sí brinda las herramientas necesarias para que se dé la vulneración, transmisión o comunicación al público de contenidos o materiales de terceros que infringen el derecho de autor, razón por la cual deben trabajar en el desarrollo de un frente que combata de forma adecuada la vulneración de los derechos de propiedad intelectual.

Una solución tanto para Colombia como para España podría ser implementar el sistema de notificaciones y contra notificaciones adoptado en el modelo Estadounidense, donde el Estado asume un rol más intervencionista dentro de la relación entre el psı y el autor, lo cual es una estrategia válida y muy importante frente a la lucha por contrarrestar el efecto de la vulneración de los derechos de autor en el Internet.

\section{CONSIDERACIONES FINALES: PAUTAS PARA UNA MEJOR PROTECCIÓN DE LOS DERECHOS DE AUTOR EN EL ENTORNO DIGITAL EN COLOMBIA}

Es importante entender que las industrias protegidas por los derechos de autor están enfocando sus negocios hacia las nuevas tecnologías, a tal punto que el negocio digital por medio de Internet es hoy en día su principal fuente de ingresos, pues los costos de distribución son muy bajos y les ofrece la posibilidad de expandirse hacia nuevos mercados, con menos obstáculos operativos y financieros. Así mismo, puede realizarse desde cualquier lugar del mundo de una manera rápida, y reproducirse de manera masiva y ágil.

A lo largo de este trabajo nos hemos enfocado en analizar el estado del arte de los derechos de autor y conexos en el entorno digital y el Internet, demostrando que en el ordenamiento jurídico colombiano existen innumerables vacíos que no permiten una verdadera protección de estos derechos. Sin embargo, si continuamos en la lectura del análisis de nuestra investigación, podemos concluir que la normatividad existente no está siendo aplicada de manera adecuada, razón por la cual la solución no se encuentra en ponerle la carga de esta problemática al legislador, sino en aplicar apropiadamente las normas de que se dispone actualmente, aunque es indudable que el principal problema es su desconocimiento. 
¿Cómo pueden protegerse actualmente en Colombia los derechos de autor en el entorno digital y el Internet?

La principal herramienta para afrontar la incertidumbre jurídica existente en nuestro ordenamiento debe enfocarse en la creación de canales de capacitación a los operadores jurídicos, en los cuales se les brinde asesoría acerca de la normatividad aplicable en la materia cuando se enfrenten a temas relacionados con infracciones realizadas en el entorno digital y el Internet.

En Colombia se necesita exhaustividad y coherencia en la respuesta normativa por parte de los operadores jurídicos, dado que la legislación resulta limitada a la hora de ofrecer una respuesta integral en un campo que se encuentra en constante cambio. La capacitación a los operadores jurídicos debe orientarse a que estos entiendan la problemática y las nuevas formas en las que se generan infracciones a los derechos de autor, y a la debida aplicación de las normas existentes, desde el marco internacional hasta el ordenamiento interno. Con ello habrá una protección mucho más efectiva y mayor seguridad jurídica, sin necesidad de crear nuevas leyes ni desgastar el aparato legislativo.

Así mismo, consideramos que tomando como ejemplo casos como el de los Estados Unidos, debemos trabajar para crear precedentes jurisprudenciales que motiven a los operadores jurídicos a aplicar nuevos conceptos, como la reproducción y la puesta a disposición de obras en Internet, con el fin de que brinden una mayor protección. En los fallos jurisprudenciales las sanciones deben ser proporcionales a la infracción cometida, sin pretender que solo se castiguen aquellos actos que hayan generado un impacto social relevante, porque de esta forma no se lograría una protección efectiva.

Esto tiene que ir de la mano con otros intervinientes en esta problemática, como las sociedades de gestión colectiva, que tienen el deber de adaptar su infraestructura a la situación actual si desean ser eficientes. Ello implica salir de la gestión territorial y contemplar el mundo plurijurisdiccional que plantea el Internet y su permanente crecimiento gracias a la tecnología digital.

De este modo, es necesaria la adaptación a una infraestructura que permita la concesión de licencias globales de explotación de las obras intelectuales en Internet, de forma simple y legal. El estado debe centrarse en garantizar que el acceso legal a las obras sea tan fácil como lo es la oferta ilegal. Sobre este punto, consideramos de gran importancia que el Estado brinde seguridad para las transacciones en línea y que fomente e incentive los sitios que ofrecen el servicio de descargas de contenido legal, con el fin de aumentar la oferta y facilitar el acceso por parte de los usuarios. Así mismo, las industrias protegidas por los derechos de autor deben hacerse partícipes y fomentar por medio de incentivos las transacciones legales por Internet, ofreciendo contenido especial o descuentos a futuro.

\section{¿Cómo evitar cometer infracciones en Internet?}

Actualmente cualquier persona que reproduzca, distribuya, comunique y ponga a disposición del 
público una obra sin autorización expresa del titular de los derechos está cometiendo una infracción. Sin embargo, es preciso advertir que de acuerdo con la regla de los tres pasos, al determinar las excepciones y limitaciones es necesario evaluar: a) que se trate de un caso especial y taxativamente establecido en la Ley (Decisión Andina 351 o Ley 23 de 1982); b) que no se atente contra la normal explotación de la obra, y c) que tal limitación no cause perjuicio injustificado a los legítimos intereses del titular o titulares de los derechos.

El panorama que nos ofrece el derecho penal en la actualidad no es muy diferente. Este entiende que cualquier conducta que afecte los derechos patrimoniales o morales de los titulares de los derechos de autor es una infracción penal. Es preocupante que no se haya revaluado el juicio de antijuridicidad, con el fin de determinar en qué momento la infracción es relevante para el derecho penal, dado que si una persona reproduce una canción en Internet sin la debida autorización del titular de los derechos estaría cometiendo un delito penal, pero la lesividad de la conducta debe tener un juicio de reproche más amplio, debido a que la afectación al bien jurídico protegido podría ser prácticamente nula.

De tal modo, la legislación penal en materia de derechos de autor y conexos debe tener en cuenta la cultura de Internet. En referencia a las elevadas tasas de descarga ilegal, para cambiar la forma de proceder debemos reformular la pregunta que la gente se hace acerca del derecho de autor e Internet. Los usuarios no reaccio- nan bien si se los tacha de piratas, pero si se les plantea el desafío de compartir la responsabilidad y de construir una política cultural podrían hacer parte de la solución. Deberíamos hacer menos referencia a la piratería y enfocarnos en dimensionar y visibilizar el efecto económico que esta representa para la viabilidad financiera y cultural del país.

El Estado debe, además de garantizar la debida protección de los derechos de autor y conexos, enfocarse en encontrar formas de concientizar a las personas sobre el daño que le causan al país cuando comenten infracciones al derecho de autor, y ofrecer incentivos a quienes accedan legalmente al contenido protegido.

Además de lo anterior, se deben realizar campañas educativas con los servidores públicos, sobre los medios jurídicos vigentes y la forma en que deben ser analizados los derechos de autor y conexos en los medios digitales; con los autores y creativos para que conozcan sus derechos y entren en la cultura del registro de las obras y de la aplicación de las herramientas con que cuentan para proteger sus derechos, porque parte del problema es la falta de precedente judicial, que se da porque el autor piensa que la vulneración es inevitable.

Es importante entender que dentro de la protección a los derechos de autor hay varios actores involucrados y que su efectividad no depende únicamente de la labor legislativa. El primero y el más importante es el creador mismo. Él es quien debe conocer y reclamar sus derechos, registrar su obra como medio de prueba y capa- 
citarse sobre las normas y mecanismos con los que cuenta para este propósito.

Del mismo modo, consideramos que para encontrar soluciones efectivas a un tema tan complejo como la protección de los derechos de autor en el entorno digital y el Internet, deben establecerse los deberes y obligaciones de todos los intervinientes (las industrias, los autores, los usuarios, los proveedores de servicios y de contenido, el Estado y los operadores jurídicos), con el fin de encontrar un verdadero equilibrio entre la protección de los derechos de autor y el acceso al contenido cultural de forma legal y económicamente viable para todos.

\section{Bibliografía}

ANTEQUERA PARILLI, Ricardo. El derecho de autor en el entorno digital. En: Revista de Derecho Privado. Diciembre de 2002, vol. 16, n. ${ }^{\circ}$ 29, p. 1-35.

CIVIL JUDGMENT OF BEIJING HAIDIAN DISTRICT PEOPLE'S COURT. China Court Cases on Intellectual Property Rights. En: The Chinese People's Public Security University Press. (January 2002). Disponible en: lawspace.law. uct.ac.za/dspace/bitstream/2165/276/1/ BechleT_2006.pdf

COLOMBIA. Ley 23 de 1982, artículo 30.

COMUNIDAD ANDINA DE NACIONES. Decisión Andina 351 de 1993.
CONFEDERACIÓN INTERNACIONAL DE SOCIEDADES DE AUTORES Y COMPOSITORES. InfOrmation networks. 12/04/07. Disponible en: http://www.cisac.org/CisacPortal/consulterArticle.do?id=269 Consultado el 16 de mayo de 2011.

CORTE CONSTITUCIONAL. Sentencia C-276 de 1996.

Sentencia C-355 de 2006.

. Sentencia C-833 de 2007.

CORTE SUPREMA DE JUSTICIA. Sentencia del 19 de enero de 2006. Radicado 23.483.

DIRECCIÓN NACIONAL DE DERECHOS DE AUTOR. Concepto Jurídico n. ${ }^{\circ}$ 1-2011-2286 del 20 de enero de 2011.

. Concepto jurídico n. ${ }^{\circ}$ 1-2001-1010, del 11 de enero de 2011. . Concepto jurídico n. ${ }^{\circ}$ 1-2011-7356, del 11 de febrero de 2011. . Concepto jurídico n. ${ }^{\circ}$ 1-2010-8227 del 1 de marzo de 2010. . Derecho de autor y derechos conexos en Colombia. Aspectos normativos. Bogotá: Convenio Antipiratería para Colombia, 2004.

ESPAÑA. Ley Española de Propiedad Intelectual n. ${ }^{\circ} 22$ de 1987. Título: Formas o actos especiales de comunicación pública. 
FÍCSOR, Mihály. Nuevas orientaciones en el plano internacional: los nuevos Tratados de la OMPI sobre derecho de autor y sobre interpretaciones o ejecuciones y fonogramas. En: Memorias del III Congreso Iberoamericano sobre Derecho de Autor y Derechos Conexos. Tomo 1. Montevideo, 1997.

FITZGERALD, Anne; CIFUENTES, Christine. Accomodating Computer Software to Copyright Doctrine: Defining the Scope of Copyright Protection for Software. En: Journal of Law, Information and Science. 2000-2001, vol. 11, n. ${ }^{\circ}$ 2.

GURRY, Francis. El futuro del derecho de autor. Conferencia en la Facultad de Derecho de la University of Technology de Queensland Australia. Disponible en: http://www.wipo.int/ pressroom/es/articles/2011/article_0005. html Consultado el 25 de febrero de 2011.

HERNÁNDEZ MARTÍNEZ, William David. La contratación por medios electrónicos en el marco de la Comunidad Andina. Estado del arte. En: Civilizar, julio-diciembre de 2009, vol. 9, n. ${ }^{\circ} 17$, p. 89-116.

HOCSMAN, Heriberto Simón. Negocios en Internet. Buenos Aires: Editorial Astrea, 2005.

http://fundacioncopyleft.org/es/9/que-es-copyleft. Consultado el 13 de mayo de 2011.

http://marketing.es/estadisticas-de-uso-defacebook-por-paises/ Consultado el 24 de mayo de 2011. http://rafamemmel.com/2009/estadisticascrecimiento-internet/ Consultado el 24 de mayo de 2011.

https://creativecommons.org/licenses/. Consultado el 24 de mayo de 2010.

LAUREN GIBBONS, Paul. Current copyright law doesn't adequately cover the Internet. En: PC Week, 27 de enero de 1997. Disponible en: http://www.securityonline.com/info/pcweek. html, cosultado el 9 de mayo de 2011.

LIPSZYC, Delia. Nuevos temas de derecho de autor y derechos conexos. Buenos Aires: Zavalía, 2004.

LÓPEZ BETANCOURT, Eduardo. Teoría del delito. México: Porrua, 1994.

MACHICADO, Jorge. Teoría del delito. Disponible en: http://jorgemachicado.blogspot. com/2009/03/teoria-del-delito.html

OLARTE, Jorge y ROJAS, Miguel. La protección del derecho de autor y los derechos conexos en el ámbito penal. Bogotá: Dirección Nacional de Derechos de Autor, 2010.

ORGANIZACIÓN MUNDIAL DE LA PROPIEDAD INDUSTRIAL. Tratado del OMPI sobre Interpretación o Ejecución y Fonogramas. . Decisión concertada, respecto del artículo 8 del Tratado OMPI sobre Derechos de Autor. 
. Declaración concertada de los artícu-

los 6 y 7, del Tratado de la OMPI sobre derecho de autor (TODA).

- Glosario de la oMPI de derecho de autor y derechos conexos. Ginebra: ompI, 1980.

. La contribución económica de las industrias del derecho de autor y los derechos conexos en Colombia. Bogotá: OMpl, 2008.

- Tratado sobre la Propiedad Intelectual respecto de los Circuitos Integrados. Washington, 26 de mayo de 1996.

ORGANIZACIÓN MUNDIAL DEL COMERCIO. Acuerdo sobre los Aspectos de los Derechos de Propiedad Intelectual relacionados con el Comercio. 1994.

PARRA TRUJILLO, Eduardo de la. El derecho sui generis sobre las bases de datos en México y la Unión Europea. En: Derecho comparado de la información. Enero-junio de 2004, n. ${ }^{\circ}$ 3, p. 101-124.

RENGIFO GARCÍA, Ernesto. Propiedad intelectual. El moderno derecho de autor. Bogotá: Universidad Externado de Colombia, 1998.

RICO CARRILO, Mariliana. Derecho de las nuevas tecnologías. Buenos Aires: Roca Editorial, 2007.

RÍOS RUIZ, Wilson. La propiedad intelectual en la era de las tecnologías. Bogotá: Universidad de los Andes y Temis, 2009.
SUPERINTENDENCIA DE INDUSTRIA Y COMERCIO. Diseños industriales. Esquema de trazado de circuitos integrados. Secretos empresariales. Bogotá: Ministerio de Comercio, Industria y Turismo, 2008.

SUPREME COURT OF THE UNITED STATES. National Geographic Society, et al. vs. Jerry Greenberg, et al. 01-186, Supreme Court of The United States, 122 S. Ct. 347; 151 L. Ed. 2d 262; 2001 U.S. LEXIS 9493; 70 U.S.L.W. 3267, October 9, 2001, decided. Disponible en: www.wipo.int/copyright/en/ecommerce/ ip.../chap3.html

TEJEIRA, Ofelia. Defensor del internauta. La Ley Sinde no es lo que parece, ahora es peor. Disponible en: http://www.internautas.org/ html/6541.html.

TOBÓN FRANCO, Natalia y VARELA PEZZANO, Eduardo. Derechos de autor para creativos. Bogotá: Grupo Editorial Ibáñez, 2010.

TRIBUNAL DE JUSTICIA DEL ACUERDO DE CARTAGENA. Sentencia 2-IP-88.

UNITED STATES COPYRIGHT OFFICE. Digital MiIlennium Copyright Act. Pub. L. n. ${ }^{\circ}$ 105-304, 112 Stat. 2860 (1998).

UNITED STATES DISTRICT COURT. The New York Times, Co. V. Tasini, (00-201) 206 F.3d 161; affirmed, United States District Court S.D.N.Y. 93 Civ. 8678 (SS), decided August 13, 1997. Disponible en: http://supct.law.cornell.edu/ supct/html/00-201.ZS.html. El 12 de mayo de 2011. 
VINENT, Magdalena. Propiedad intelectual, la razón. Disponible en: http://www.cedro.org/ textos_interes_ambito_digital.asp

WORLD INTELLECTUAL PROPERTY ORGANIZATION. The Impact of Internet on Intellectual Property Law. Introduction to digital co- pyright. Disponible en: http://www.wipo.int/ copyright/en/ecommerce/ip_survey/chap3. html\#_ftn66, el 9 de mayo de 2011.

ZAFFARONI, Eugenio Raúl. Manual de derecho penal. Parte general. México: Cárdenas, 1991. 